\title{
Reuna
}

\section{DESENVOLVIMENTO E EDUCAÇÃO A DISTÂNCIA: UMA ANÁLISE DO EMPREENDEDORISMO NAS CIDADES INTERIORANAS DE BRASIL E PORTUGAL}

\section{DEVELOPMENT AND DISTANCE EDUCATION: AN ANALYSIS OF ENTREPRENEURSHIP IN COUNTRYSIDE CITIES OF BRAZIL AND PORTUGAL}

\author{
http://dx.doi.org/10.21714/2179-8834/2020v25n2p33-52
}

\author{
Karin Vieira da Silva \\ Universidade do Estado de Santa Catarina (UDESC), Brasil. \\ E-mail: vieira.karin@gmail.com \\ Cristina Martins \\ Centro Universitário Municipal de São José (USJ), Brasil. \\ E-mail: crismartins2611@gmail.com \\ Anderson Sasaki Vasques Pacheco \\ Universidade do Estado de Santa Catarina (UDESC), Brasil. \\ E-mail: sasaki.anderson@gmail.com
}

Submissão: 10 Abr. 2020. Publicação: 30 Jun. 2020. Sistema de avaliação: Double blind review. Centro Universitário UNA, Belo Horizonte - MG, Brasil. Editor geral: Prof. Dr. Thiago Soares Nunes

Este artigo encontra-se disponível nos seguintes endereços eletrônicos:

http://revistas.una.br/index.php/reuna/article/view/1143

http://dx.doi.org/10.21714/2179-8834/2020v25n2p33-52

\section{Resumo}

O empreendedorismo vem sendo apresentado como uma alternativa potencial para o fomento do crescimento econômico e do desenvolvimento. Nesse âmbito, acredita-se que as instituições de ensino superior podem contribuir substancialmente ao criarem condições favoráveis para o estímulo do empreendedorismo entre os seus alunos. Assim, o objetivo deste artigo é analisar os índices de empreendedorismo entre os alunos diplomados em administração/gestão da Universidade Aberta do Brasil e de Portugal, em regiões específicas no interior de ambos os países. Para tanto, foram realizadas entrevistas e aplicados questionários em diplomados entre os anos de 2010 e 2014, residentes em seis cidades brasileiras e quatro portuguesas. Os dados qualitativos foram tratados por meio da análise de conteúdo e os quantitativos mediante análise descritiva e testes de associação. Os resultados sugerem que, embora a relação entre universidade e desenvolvimento de empreendedores, e igualdade de gênero careça de maior robustez, sobretudo no Brasil, a educação a distância apresenta contributos para o desenvolvimento de tais regiões, uma vez que os consideráveis índices de empreendedorismo entre os alunos podem contribuir para dinamizar os arranjos sociais e econômicos locais.

Palavras-chave: Empreendedorismo; Educação a distância; Desenvolvimento; Igualdade de gênero. 


\begin{abstract}
Entrepreneurship has been presented as a potential alternative to promote economic growth and development. In this context, we believe that higher education institutions can substantially contribute to economic development, by generating favorable conditions to stimulate entrepreneurship among their students. Thus, the objective of this article is to analyze the entrepreneurship rates between the graduates in management of the Brazil and Portuguese Open Universities, in countryside regions. Therefore, interviews were conducted, and questionnaires were applied with graduates between the years 2010 and 2014, in six Brazilian municipalities and four Portuguese cities. Qualitative data were treated through content analysis and quantitative data using descriptive analysis and association tests. The results shows that although the relationship between university and entrepreneurship development, and gender equality are fragile, mainly in Brazil, distance education can contribute to the development of such regions, since graduates entrepreneurship can contribute to invigorate local social and economic arrangements.
\end{abstract}

Keywords: Entrepreneurship; Distance education; Development; Gender equality.

\title{
1. Introdução
}

O empreendedorismo é visto, muitas vezes, como uma das alternativas para o crescimento econômico e desenvolvimento de modo geral. Em suas diversas manifestações, ele pode fortalecer as economias locais, por meio da criação de novos negócios, ser uma opção frente a situações de desemprego, criar novas dinâmicas dentro das organizações, mediante a ação de intraempreendedores, e fortalecer a sociedade civil, através da inovação e do empreendedorismo social.

Entretanto, a atividade empreendedora não deve ser vista apenas como uma ação promovida exclusivamente por sujeitos que carregam consigo o "espírito empreendedor", ou seja, como algo inato, que não pode ser desenvolvido e aperfeiçoado ao longo dos anos. Ao contrário, o empreendedorismo envolve diversas variáveis que demandam conhecimentos e competências específicas, e pode ser fomentado por meio de ações educativas destinadas a este fim.

Nesse âmbito, Tezza, Silveira e Hoeltgebaum (2006, p. 48) ressaltam que "é papel das Instituições de Ensino Superior (IES), o desenvolvimento de competências empreendedoras e a disseminação da cultura do empreendedorismo". Ribeiro, Oliveira e Araújo (2014) corroboram essa perspectiva ao destacarem que a disseminação do espírito empreendedor deve ser também responsabilidade de instituições de ensino superior, uma vez que a educação empreendedora pode se propagar pela sociedade e impactar significativamente a geração de emprego, renda e o desenvolvimento econômico.

No campo das ciências da administração, o empreendedorismo desponta como uma relevante área de ensino e pesquisa, materializando-se em disciplinas exclusivas nos cursos de graduação e pós-graduação voltados aos interessados em atuar nesta área, além de linhas de pesquisa dedicadas ao seu estudo em programas de mestrado e doutorado (SILVA; GIL, 2015).

Segundo Henrique e Cunha (2006, p. 2), incluir a temática do empreendedorismo em cursos de administração potencializaria a formação de: 
(...) pessoas arquitetadas de conhecimentos para estar aptos a abrir um negócio, um empreendimento, assim como buscar inovações dentro das empresas em que trabalham, atuando como intraempreendedores, e contribuindo para a contínua inserção e sobrevivência das organizações dentro de ambientes cada dia mais complexos.

Para além disso, Souza et al. (2006) salientam que fomentar o perfil empreendedor nos alunos permite "capacitá-los para a criação, condução e implementação do processo criativo, proporcionando a oportunidade de elaborar novos planos de vida, de trabalho, de estudo e de negócios", e, desta forma, potencializar a capacidade de se tornarem atores responsáveis pelo seu próprio desenvolvimento pessoal (OLIVEIRA; MELO; MUYLDER, 2016, p.37).

Portanto, a educação pode atuar como propulsora da atividade empreendedora ao dotar os seus alunos dos conhecimentos e competências necessárias para a abertura de um novo negócio ou ainda promover mudanças substanciais dentro das organizações e da sociedade em que atuam. Quando se fala em regiões onde a economia é pouco diversificada e as possibilidades de trabalho também não são abrangentes, as variáveis educação e empreendedorismo ganham ainda mais relevância ao surgirem como possibilidades de transformação econômica e social.

Nesse contexto, o objetivo deste artigo é analisar os índices de empreendedorismo entre os alunos diplomados em administração/gestão da Universidade Aberta do Brasil e de Portugal, em regiões interioranas de ambos os países. Além desse objetivo central, procurou-se verificar a existência de associação entre gênero e empreendedorismo nos diplomados de ambos os países.

Sobre a contribuição deste artigo, outras pesquisas relatam o papel dos cursos de administração na modalidade a distância para o desenvolvimento de competências e do espírito de empreendedor (CRISSIEN, 2013; MAURO et al., 2017; SOLORZANOGARCÍA; NAVÍO-MARCO, 2019). Dando um passo adiante ao escopo das competências, este artigo oferece indicativos para futuras pesquisas que atuam na perspectiva de avaliação dos efeitos, em termos de comportamento realizados do ato de empreender, após o período da graduação.

\section{Fundamentação teórica}

Os referenciais teóricos que sustentam esta pesquisa estão relacionados com o seu contexto e objetivos, sendo esses a temática da educação a distância e o conteúdo sobre educação empreendedora das universidades.

\subsection{Educação a distância}

A concepção histórica da educação a distância é compreendida basicamente em cinco gerações. A primeira delas e, de origem, está relacionada a ideia de utilização da tecnologia disponível para prover acesso à educação aqueles que de alguma outra forma não o teriam, por isso, sua relação inicial aos cursos de instrução realizados via correios ou conhecidos como cursos por correspondência (MOORE; KEARSLEY, 2012). A segunda geração está ligada a ampliação dos novos recursos de comunicação via transmissão a rádio e televisão, esta última obtendo maior êxito dada as significativas contribuições financeiras da Ford (MOORE; KEARSLEY, 2012). 
A terceira geração vincula-se as novas formas de organização de diferentes tecnologias de comunicação e de recursos humanos, visando oferecer ensino gratuito e de qualidade. A teleconferência marca a quarta geração, pois com a utilização da fibra ótica se conseguiu expandir os sistemas de transmissão de áudio e vídeo possibilitando a primeira interação em tempo real entre alunos e professores/tutores (MOORE; KEARSLEY, 2012).

A quinta e, atual geração é baseada nas aulas virtuais suportadas por computador e pela internet, que permitem convergência de diversas mídias (texto, áudio, vídeo, etc.) numa única plataforma de comunicação (MOORE; KEARSLEY, 2012). Esta nova geração ampliou as possibilidades de estudar a distância e permitiu uma maior interação entre atores envolvidos no processo educativo (SIMONSON, 2006). como um

Neste sentido, conceitualmente a educação a distância pode ser compreendida

processo de ensino-aprendizagem mediado por tecnologias, onde professores e alunos ficam "separados" espacial e/ou temporalmente. Podem envolver atividades presenciais e outros momentos de "contatos" conjuntos, porém, ligados ou intermediados através de recursos tecnológicos (HERMIDA; BONFIM, 2006, p. 168).

Comumente confundida com e-learning, chama-se a atenção que a "distância" não caracteriza e-learning, pois este último é mais empregue por estudantes no campus como uma ferramenta facilitadora das interações EAD. Além disso, há diferenças conceituais entre "ensino" e "educação", sendo o primeiro relacionado às atividades instrumentais (treinamento e instrução), enquanto o segundo está relacionado ao processo educativo, buscando o desenvolvimento do aluno no processo de construção do conhecimento (GURI-ROSENBLIT, 2005).

Assim, Moore e Kearsley (2012, p. 02) esclarecem que a expressão "educação a distância" é frequentemente utilizada quando se pretende focar não somente a aprendizagem, mas incluir também o ensino.

Neste sentido, Aretio (1997) informa que a modalidade de ensino a distância difundiu-se amplamente devido à necessidade de atender a um público diferenciado que, por inúmeros motivos, tais como conciliar trabalho, família e estudo, não pode se afastar do seu local de trabalho ou morada para chegar às instituições de ensino.

Portanto, são características dos estudantes a distância a heterogeneidade da faixa etária, problemas em relação a localização geográfica, já se encontram inseridos no mercado de trabalho, tem o estudo como atividade secundária, geralmente realizados em casa ou no trabalho, a aprendizagem é independente, tem menor interação social e o currículo é determinado pelo estudante (ARETIO, 1997).

Tal afirmação está de acordo com Nunes (2009), que argumenta que a educação a distância apresenta grande potencial para a democratização do ensino, pois atinge regiões de difícil acesso, o que possibilita a aprendizagem em locais periféricos e confere ainda uma forma alternativa de estudo para pessoas que não têm condições de se adaptar ao ensino presencial.

Formiga (2009, p. 39) salienta que a educação a distância está intimamente relacionada com as tecnologias da informação e comunicação e se constitui como um setor com grande dinamicidade "que transforma, moderniza e faz caducar termos 
técnicos e expressões linguísticas em velocidade alucinante". Além disso, o autor destaca que "a sociedade da informação e do conhecimento se reflete na EaD pela apropriação célebre dos conceitos e inovações, que moldam a média e refletem-se na própria EaD".

Entretanto, há críticas quanto as interações estabelecidas por meio dos aparatos tecnológicos, segundo Silva (2014), estes não proporcionam uma real comunicação, pois privam os alunos de estabelecerem vínculos e dificultam o processo educativo.

Em concordância, Lück (2008) argumenta que, na educação a distância, o professor tem o seu papel reduzido e é por vezes desvalorizado, sendo o trabalho docente remetido à precarização. Todavia, essa afirmação é rebatida pelo próprio autor ao dizer que tal situação é superada quando se pretende oferecer uma proposta de formação de qualidade, incluindo profissionais de diferentes áreas e as tecnologias disponíveis" (LÜCK, 2008, p. 261). Franco (2003) também apresenta um contraponto a essa crítica ao declarar que ela não é uma especificidade do modelo a distância, pois afeta a educação em geral.

Em adendo, no caso da educação a distância, a adoção da lógica de mercado e a consequente mercantilização da educação emergem como uma problemática, mas que também não se limitam a ela, pois abrangem a educação em geral (SILVEIRA, 2011)

Neste contexto, Lapa (2007) descreve que é preciso refletir sobre o potencial concreto da educação a distância na promoção da interação social e da construção coletiva do conhecimento, assim como é imprescindível o desenvolvimento de métodos que propiciem um ambiente no qual a ação dialógica possa desenvolver-se, ao promover práticas sociais capazes de favorecer uma formação crítica mediada pelas tecnologias.

O movimento de transformação da educação a distância passa pelo processo de consciência e ação dos atores envolvidos relativamente às estruturas que permeiam muitos dos cursos oferecidos, nos quais a formação está limitada à técnica e voltada para o atendimento das demandas laborais. Em razão dos apontamentos realizados nesta seção, julga-se importante compreender como as universidades podem atuar na promoção de aspectos transversais a formação de novos administradores, que irão atuar tanto profissionalmente, no âmbito de empresas públicas e privadas, como cidadãos, na esfera da sociedade civil.

\subsection{A Educação empreendedora das Universidades}

O mundo da educação superior encontra-se em efervescência, assinala Morosini (2011). Por um lado, o declínio do monopólio do conhecimento na universidade e em suas antigas funções e, por outro lado, a existência atual de uma diversidade de modelos de universidades e tipos de conhecimento. Passou-se a contestar o conhecimento global e a reconhecer a importância dos conhecimentos locais (MOROSINI, 2011). A sociedade começou a observar atentamente a universidade como um agente promotor da cultura e das práticas empreendedoras e inovadoras, pois conforme Sarkar (2008, p. 68) estas " [...] tem tradição longa em ser um ninho de empreendedores". 
Neste sentido, o modelo da universidade empreendedora, compreendida também como uma universidade inovadora vem chamando a atenção, pois em sua essência é (MOROSINI, 2011, p.195):

[...] criativa; envolve-se com a sociedade local; comunica-se bem com seus vários públicos; assume riscos; orienta-se pela qualidade; preocupa-se com sua reputação. Para tanto, estabelece novos convênios; cria estratégias para aumentar o número de bolsas; desenvolve pesquisas de qualidade; cria novos serviços no campus; busca e valoriza a colaborações de ex-alunos. Uma universidade empreendedora terá que ser uma universidade inovadora.

Conforme se referia o pai da inovação Schumpeter (1911/1982), o empreendedor é aquele que aplica a inovação. Esta concepção de ligação entre os fenômenos gera interpretações como a de Sarkar (2008), que coloca que a definição histórica de inovação, "a obtenção de uma nova função de produção" (SHUMPETER, 1939, p.83) é o mesmo que atualmente se entende por empreendedorismo. Desta forma, observa-se atualmente a tendência de caracterizar empreendedorismo e inovação como agentes integrados (COSTA; BARBOSA; SILVA, 2011).

Assim, o empreendedorismo e a inovação não existem sem conhecimento. $A$ junção destes três elementos é ilustrada por Cavalcanti e Gomes (2001, pag. 56) em formato de triângulo na Figura 1.

Figura 1 - Gestão da nova economia

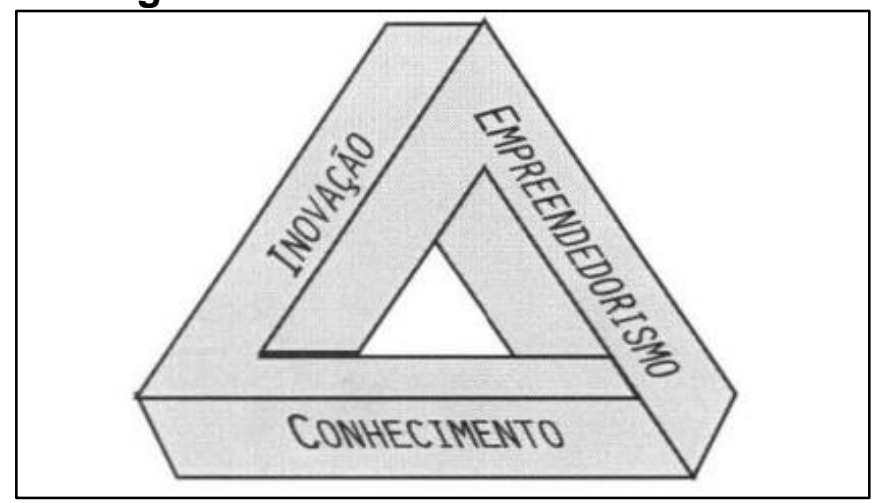

Fonte: Cavalcanti e Gomes (2001, p. 56).

Tanto o empreendedorismo quanto a inovação são gerados pela criação, manutenção, compartilhamento e a utilização do conhecimento. Entretanto, o conhecimento nasce dos investimentos em educação. Consequentemente, as universidades assumem um papel fundamental neste processo (COSTA; BARBOSA; SILVA, 2011), sendo elas, os agentes mais indicados não só por sua capacidade, responsabilidade em questões relativas ao meio ambiente e problemas econômicos e sociais, mas também por questões de avanços educacionais e de desenvolvimento tecnológico (CASADO; SILUK; ZAMPIERI, 2012).

Desta forma, a universidade tem entre seus desafios a renovação, pois como um ambiente propício para o desenvolvimento de inovações (ETZKOWITZ, 2002) tem no fenômeno a possibilidade de aplicação tanto nos serviços oferecidos por ela, quanto nos seus processos, nas tecnologias empregadas, nas práticas de ensino e de gestão, nos negócios ou nos investimentos institucionais, etc. $O$ processo de inovação, portanto, deve ser valorizado e incentivado pela universidade para que a melhoria continua possa se instalar como prática corrente na instituição (CASADO; SILUK; ZAMPIERI, 2012). 
Em consonância, Sarkar (2008) traz a visão que a universidade empreendedora é voltada para estudantes não-tradicionais com ênfase no desenvolvimento de serviços em uma perspectiva prática, em formatos alternativos (tempo, lugar, tecnologia) em múltiplas localizações, ultrapassando a concepção tradicional de campus e salas de aula, mas buscando atender novos eleitorados por meio de colaborações e parcerias.

Segundo Costa, Barbosa e Silva (2011) a prática da formação do empreendedor já se confirmou em países desenvolvidos tal como nos Estados Unidos, que há muitos anos investem em educação. Resultado disso, são as três maiores instituições de ensino do mundo, $1^{\text {a }}$ - Massachusetts Institute of Technology; 2 ${ }^{\text {a }}$ Harvard University; e $3^{\text {a }}$ Stanford University. Nestas universidades há uma preocupação constante com o empreendedorismo e a inovação, por isso é fomentada a participação de pesquisadores nas indústrias e a cooperação entre os diversos agentes, especialmente universidades, empresas e o governo.

Para Ferreira (2000), esta cooperação faz com que grandes universidades e centros de excelência gerem novas tecnologias, que possam contribuir para o avanço da qualidade, e consequentemente, da competitividade do setor produtivo, auxiliando ainda no surgimento de novos empreendimentos inovadores, o que trará um significativo impacto positivo para a economia do país.

$\mathrm{Na}$ Ásia o investimento em educação é proporcional ao seu crescimento, especialmente na educação superior, deste modo países como China passam a desenvolver pesquisa dentro das próprias universidade para a posteriori comercializar seus resultados (COSTA; BARBOSA; SILVA, 2011).

Nesses países, portanto, há um latente crescimento no investimento em educação empreendedora e, que ocorre também, nas plataformas à distância (PENEDO; PEREIRA, 2018). Na América do Sul, com destaque para o Brasil, os investimentos em empreendedorismo e inovação ainda são tímidos se comparados a outros continentes (sobretudo a Ásia). De qualquer forma, a inovação está atrelada ao processo de incubação de empresas, algo que vem crescendo e acontece também dentro de algumas universidades brasileiras (ETZKOWITZ; MELLO; ALMEIDA, 2005).

Todo este movimento concretiza a importância do espírito empreendedor para se gerar inovações que serão importantes para o progresso da humanidade e da importância inquestionável da educação e das universidades para o nascimento deste espírito empreendedor, principalmente na comunidade acadêmica (COSTA; BARBOSA; SILVA, 2011).

Por fim, lembra-se que o relacionamento dentro das universidades se torna um importante fator para as ideias empreendedoras e para a criação de inovação. Devese incentivar o empreendedorismo dentro das universidades, local em que o conhecimento norteia todas as ações, pois as chances de criação de produtos e processos inovadores serão mais concretas. É nesse contexto que se insere o objetivo deste estudo, que busca compreender a expressão do empreendedorismo entre os egressos de cursos a distância, no interior de Brasil e Portugal, e dar indicativos sobre possíveis contribuições para o desenvolvimento destas regiões. Para tanto, foi utilizada uma metodologia de pesquisa específica, que será descrita a seguir. 


\section{Metodologia}

Nesta pesquisa foram utilizadas as abordagens quantitativa e qualitativa. Quantitativa por se tratar de um survey e, consequentemente, pela utilização de dimensões quantificáveis nos processos de recolha de dados e pelo uso de técnicas estatísticas para o seu tratamento (SOUZA; FIALHO; OTANI, 2007). A abordagem qualitativa foi utilizada pela necessidade de estudar o fenômeno de forma aprofundada, tendo em conta a relação dinâmica entre o contexto e o indivíduo, o que significa, em outras palavras, a existência de um vínculo entre as questões objetivas e as subjetivas de cada indivíduo (SILVA; MENEZES, 2001).

Assim, foram recolhidas informações por meio de questionários, entrevistas e documentos. Os questionários foram aplicados nos bacharéis do curso de administração da Universidade Federal de Santa Catarina e do curso de gestão da Universidade Aberta de Portugal. Ressalta-se que a amostra foi delimitada as regiões interioranas dos países, portanto selecionou-se as cidades de São Francisco de Paula (RS), Tapejara (RS), Tio Hugo (RS), Jacuizinho (RS), Laguna (SC) e Tubarão (SC) do Brasil; e Grândola, Porto de Mós, Ponte de Lima e Ribeira Grande (esta última na Região Autônoma dos Açores) de Portugal.

Foram selecionados os diplomados que terminaram o curso nos anos de 2010 a 2014, devido a primeira turma formada no Brasil datar do ano inicial referido. A taxa de respostas aos questionários foi de 47,7\% (63 de 132 responderam) no Brasil. Em Portugal, a taxa total foi de $42,5 \%$ ( 85 de 200 responderam). Ressalta-se que a amostra está acima da média de respostas habitual de inquéritos online, que, segundo Abrantes Henriques, Jacquinet e Neves (2014), está entre 10\% a $20 \%$.

A construção do questionário utilizado nesta pesquisa teve por base o inquérito aplicado pela Universidade Aberta de Portugal aos seus ex-alunos, através do projeto "Ensino Virtual, Impactos Reais: Os percursos profissionais e de vida dos estudantes da Universidade Aberta", realizado por Abrantes et al. (2014). O referido instrumento de pesquisa foi construído e alojado na plataforma Google Forms, que registra os dados em planilhas eletrônicas.

Foram realizadas vinte e quatro entrevistas com os diplomados brasileiros e vinte e três com os bacharéis portugueses. Elas foram encerradas após a consideração da saturação dos dados, que implica que as informações passem a repetir-se ou elementos novos deixem de aparecer (ALBARELLO et al., 1997). Também foram recolhidos dados documentais, para verificar quais as disciplinas que englobavam o tema empreendedorismo.

Com relação aos dados quantitativos, esses foram tratados no software SPSS, versão 22. As técnicas utilizadas foram a estatística descritiva, que se baseia na soma dos dados e criação de ferramentas de análises, tais como gráficos e tabelas (HUOT, 2002; REIS, 1996), e testes de associação e correlação entre as variáveis, ao explorar uma ou mais variáveis em conjunto, tendo em vista os objetivos do estudo (DALFOVO; LANA; SILVEIRA, 2008).

Para a realização dos testes de associação, que determinam existência de associações entre as variáveis e a sua intensidade, foi utilizado o teste de $V$ de Cramer, aplicado quando a pretensão é testar a relação entre duas variáveis qualitativas nominais ou que podem ser tratadas desta forma (LAUREANO, 2013). 
Nos testes de associações desta pesquisa, utilizamos as seguintes hipóteses para verificar a existência de associação entre as variáveis:

HO: o coeficiente de associação V de Cramer é igual a zero, ou seja, não existe relação entre o par de variáveis.

H1: o coeficiente de associação V de Cramer é diferente de zero, ou seja, existe relação entre o par de variáveis.

Assim, as regras de decisão obedeceram aos seguintes critérios: Não rejeitar H0: se Aprox. Sig. > 0,05; Rejeitar H0 (aceitar H1): se Aprox. Sig. < =0,05. Ressaltase que o grau de intensidade da associação foi determinado pelas seguintes medidas: Inexistência de relação (Aprox. Sig = 0); Insignificante (]$|0-0,2|[)$; Fraca $([|0,2-0,4|[)$; Média ([|0,4 - 0,7|[); Forte [|0,7 - 1|[]); relação determinística (|1|) (LAUREANO, 2013).

No que tange a análise de dados qualitativa, utilizou-se a análise de conteúdo "porque oferece a possibilidade de tratar de forma metódica informações e testemunhos que apresentam um certo grau de profundidade e complexidade" (QUIVY; CAMPENHOUDT, 2005, p. 227). Portanto, estas informações foram usadas em complemento a análise quantitativa, triangulando as informações para verificar a veracidade dos dados. Ressalta-se que os dados das entrevistas transcritas e os documentos foram armazenados e analisados com o software MaxQda v. 12..

\section{Estudo de caso}

Nesta seção foi apresentada, inicialmente, uma breve descrição das cadeiras dos cursos que contém conteúdo sobre empreendedorismo. Em seguida, estão dispostos os índices de empreendedorismo entre os diplomados em administração/gestão das Universidades Abertas de Brasil e de Portugal, nas localidades interioranas estudadas.

\subsection{Disciplinas de empreendedorismo nos cursos pesquisados}

A temática do empreendedorismo é trabalhada em disciplinas específicas em ambos os cursos pesquisados. No caso do curso de Administração a distância da Universidade Aberta do Brasil, oferecido pela Universidade Federal de Santa Catarina, a disciplina "Cultura Empreendedora e Criatividade" é ofertada no quarto ano do curso, precisamente no oitavo período. A disciplina é de quatro créditos, o que resulta em uma carga horária de sessenta horas. O objetivo da matéria é apresentar o "empreendedorismo como resposta ao novo conceito de empregabilidade" e o "desenvolvimento de atitudes, capacidades e habilidades empreendedoras" (BUNN; SILVA, 2014, p. 29).

Existe no curso mais uma disciplina voltada ao empreendedorismo, que se chama "Empreendimentos e Modelos de Negociação". Trata-se também de uma matéria de quatro créditos, com a carga horária de sessenta horas. Ela tem como objetivo apresentar a "importância da inovação tecnológica como diferencial competitivo para a pequena e média empresa" e aspectos relacionados à "abertura e gerenciamento de novos negócios" Essa disciplina é oferecida no quinto ano do curso, nomeadamente no nono período (BUNN; SILVA, 2014, p. 30). 
Por fim, destaca-se que na disciplina de "Direção Estratégica", o tema do empreendedorismo é colocado na ementa, em meio a outros temas, ainda que não seja o foco principal da disciplina. Tal como no caso anteiror, essa cadeira possui 4 créditos, 60 horas e é ofertada no quinto ano do curso, precisamente no nono período (BUNN; SILVA, 2014, p.30). Ainda sobre o curso de administração da UAB do Brasil, vale salientar que dentre os seus própositos gerais está "formar um profissionaladministrador dotado de capacidade analítica e empreendedora" (BUNN; SILVA, 2014, p.13).

No caso do curso de gestão a distância da Universidade Aberta de Portugal, verificou-se a existência de duas disciplinas que abordam a questão do empreendedorismo. A primeira delas trabalha o tema de forma mais direta e é chamada de "Empreendedorismo". Ela está localizada no primeiro semestre do terceiro ano de curso e possui seis ECTS (European Credit Transfer and Accumulation System') (DCSG, 2015/2016, p.22).

Os objetivos desta matéria são expostos como:

Apresentar os conceitos fundamentais relacionados com a definição de empreendedorismo e empreendedor; compreender os ambientes que favorecem o empreendedorismo; analisar e discutir diferentes tipos de empreendedorismo: social, corporativo; compreender o processo empreendedor; identificar estratégias de crescimento e de consolidação de negócios (DCSG, 2015/2016, p. 22).

A outra disciplina na qual o empreendedorismo é abordado, embora não seja o foco exclusivo, é intitulada "Projeto Empresarial" e dentre os seus propósitos está a "promover a aplicação de metodologias de ensino centradas no estudante que incentivem o desenvolvimento do espírito empreendedor" (DCSG, 2015/2016, p.23).

Dwivedi (2017) ressalta que as Instituições de Ensino Superior que oferecem cursos de gestão devem ofertar cadeiras de empreendedorismo e uma estrutura de qualidade, para orientar os futuros estudantes aos novos desafios do empreendedorismo. Desta forma, verifica-se em ambos os cursos a preocupação com a temática do empreendedorismo, estando inserida ao nível de disciplinas destinadas especificamente à área, e em outras que circundam o tema. O próximo capítulo visa verificar se as disciplinas tiveram algum papel para o desenvolvimento empreendedor dos estudantes.

\section{2 Índices de empreendedorismo entre os diplomados}

Relativamente aos índices de empreendedorismo entre os diplomados, no estudo realizado no Brasil, verificou-se que 14,3\% dos inquiridos abriram alguma empresa ou passaram a exercer uma atividade profissional por conta própria (ver Gráfico 1, a seguir). 
Gráfico 1 - Abertura de alguma empresa ou atividade profissional por conta própria - UAB/Brasil.

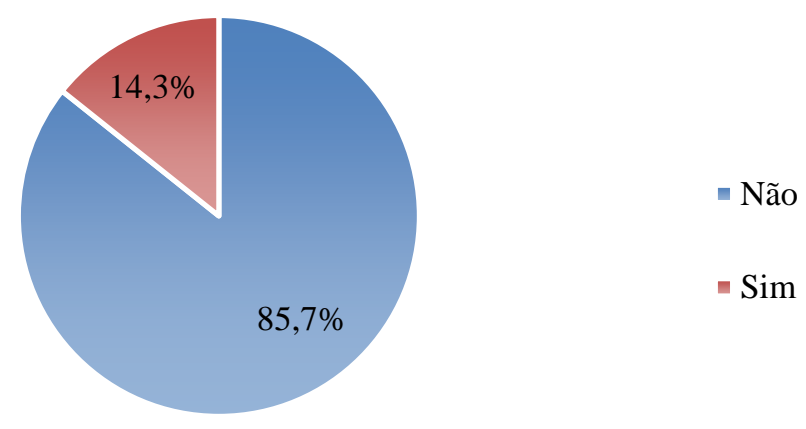

Fonte: Elaborado pelos autores.

Os relatos de alguns alunos entrevistados refletem a relação entre o curso realizado e a motivação para a atividade empreendedora, conforme se observa a seguir:

Eu sempre tive vontade de abrir uma empresa (...) um negócio, alguma coisa própria, sabe? Então, eu fui fazer o curso de administração (...) e agora eu estou lançando uma revista na minha cidade. O curso de administração ajuda muito (...) a pôr em pratica essa ideia de abrir uma empresa. E como o país está em crise, tem que ter novas ideias, fazer novas coisas (AB2).

Foi muito importante. Este curso foi minha segunda graduação. Eu realizei o curso com o objetivo de abrir meu próprio negócio (...) mas com as dificuldades recentes de crédito, ainda não consegui concretizar o meu objetivo (AB17).

O meu colega de trabalho abriu o próprio negócio (...) ele fez todo o plano de negócio e seu TCC (trabalho de conclusão de curso) na empresa que ele abriu. Assim, é uma experiência que a gente tem aqui, de alguém que está estudando e abriu uma empresa (AB10).

No caso de Portugal, a influência do curso para 0 fomento do empreendedorismo foi sentida para $14,1 \%$ dos pesquisados que disseram ter aberto uma empresa ou iniciado uma atividade profissional por conta própria, entre o início do curso e o momento da pesquisa (ver gráfico 2).

Gráfico 2 - Abertura de alguma empresa ou atividade profissional por conta própria UAB/Portugal.

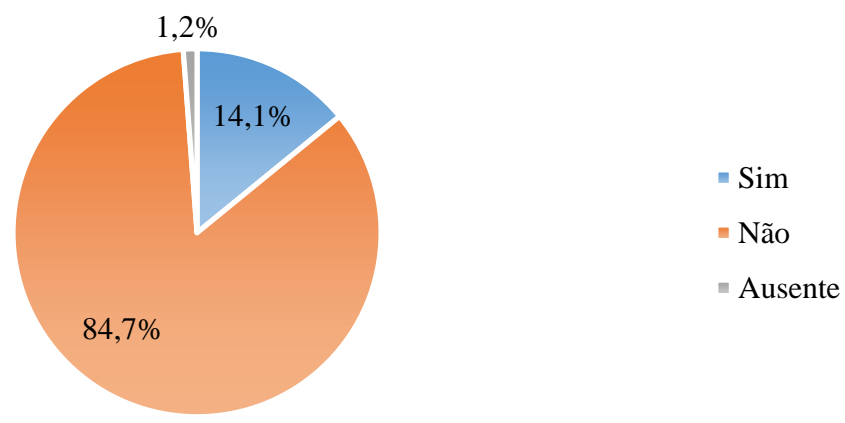

Fonte: Elaborado pelos autores.

REUUNA, Belo Horizonte - MG, Brasil, v. 25, п. 2. p. 33-52, Abr. - Jun. 2020 - ISSN 2179-88034 
No discurso dos entrevistados foi possível verificar a influência que o curso teve em alguns alunos, no sentido de despertar a vontade de abrir um negócio próprio ou, até mesmo, efetivar um empreendimento. Um dos aspetos transversais nos relatos é o ganho de maior segurança para empreender:

Eu penso que mudou totalmente o meu percurso profissional. Fez-me querer ter o meu próprio negócio, fez-me ter uma visão mais empreendedora do que já tinha anteriormente, deu-me mais confiança para abraçar novos projetos que depois abracei. E, também, em termos remuneratórios foi uma mais-valia (AP27).

Ter evoluído de funcionário para dono de uma empresa foi, de fato, uma grande diferença, claro que não foi por acaso e por vontade, foi uma fatalidade da nossa antiga empresa que nos levou a esse rumo, mas não teria a segurança que tive em fazer uma empresa se não tivesse o curso da Universidade Aberta (AP28).

Em linhas gerais, verificaram-se valores muito parecidos entre os casos pesquisados, $14,3 \%$ no Brasil e 14,1\% em Portugal. De acordo com o relatório Global Entrepreneurship Monitor - Global Report (GEM, 2015/16), em Portugal, a taxa de atividade empreendedora early-stage ii é de 9,5\%, e de proprietário-gestor de um negócio já estabelecido (com mais de 3,5 anos) é de $7 \%$, resultando numa taxa geral de empreendedorismo de $16,5 \%$. Os valores no Brasil, indicados pelo mesmo relatório, apontam para uma taxa de atividade empreendedora early-stage de $21 \%$ e de proprietário-gestor de um negócio já estabelecido (com mais de 3,5 anos) de $18,9 \%$, totalizando $39,9 \%$.

Ao comparar os valores de cada curso com a respectiva situação em relação ao empreendedorismo, há indicações de que o curso teve um maior impacto relativo em Portugal, uma vez que o país possui uma taxa de empreendedorismo em estágio inicial de 9,5\%, e $14,1 \%$ dos diplomados abriram um negócio por conta própria, estando um pouco acima à média nacional. Ressalta-se que, nos últimos anos ocorreu um aumento de empreendedores early-stage no País, crescendo o índice para cerca de 13\% (BOSMA et al., 2019).

Já no Brasil, a taxa de empreendedorismo em estágio inicial é de 18,9\%, sendo um pouco acima da encontra nos diplomados brasileiros $(14,3 \%)$. É interessante ressaltar que, nos últimos anos, houve um grande aumento da taxa de empreendedorismo no Brasil e que este índice foi muito influenciado pelo empreendedorismo por necessidade, entre os empreendedores iniciantes, pois enquanto o índice de indivíduos que abriram um novo negócio por oportunidade caiu de $71 \%$ em 2014 para 56\% em 2015, a taxa de pessoas que tomaram essa decisão por necessidade aumentou de 13\% para 36\% em 2015 para as empresas iniciantes (GEM-BRASIL, 2015). Apesar disso, destaca-se que o número de empreendedores por oportunidades no País continuou caindo em $2016(57,4 \%)$ e voltou a crescer em 2017 (59,4\%) e 2018 (61,8\%) (BOSMA et al., 2019).

Julga-se relevante salientar que os relatórios do Global Entrepreneurship Monitor apontaram duas condições limitadoras da atividade empreendedora, transversais ao Brasil e Portugal: as políticas governamentais e as condições de educação e formação. No primeiro caso, os empecilhos estão relacionados com a carência de políticas públicas adequadas às necessidades dos empreendedores. Já no segundo, a problemática está na pouca ênfase dada ao empreendedorismo em todos os níveis de educação (GEM-PORTUGAL, 2013; GEM-BRASIL, 2015). 
O Global Report do ano de 2016 demonstrou ainda que os índices de educação empreendedora não apresentam resultados robustos em ambos os países. 0 indicador avalia a educação empreendedora nos países em duas fases, "at school stage" e "at post school", e varia de 1 = altamente insuficiente a 9 = altamente suficiente. Portugal apresentou resultados melhores que o Brasil, atingindo 5,60 no estágio "at school stage" e 4,74 no "at post school". No Brasil estes índices são, respetivamente, 2,11 e 3,84 (GEM, 2015/16).

Por fim, quanto a análise da taxa de empreendedorismo, destaca-se que, apesar de outras pesquisas identificarem que a formação superior em administração na modalidade a distância pode fomentar o ato de empreender (MARKOVIĆ et al., 2017; SOLÓRZANO-GARCÍA; NAVÍO-MARCO, 2019), os resultados encontrados mostram que pode haver a existência de outros fatores para que ocorra a ação de empreender em diplomados, ou que, essas atitudes, podem estar no campo do intraempreendedorismo e suas competências (CHAN et al., 2017).

Além da taxa de empreendedorismo, com os dados coletados, procurou-se verificar a existência de associação entre as varáveis "abrir um negócio após o curso" (empreendedorismo) e "gênero". Como existem diversos estudos sobre a "masculinização" da atividade empreendedora (SHNEOR; CAMGÖZ; KARAPINAR, 2013) julgou-se oportuno estudar este aspecto. Portanto, foram formuladas as seguintes hipóteses:

H0: o coeficiente de associação $V$ de Cramer é igual a zero, ou seja, não existe relação entre o par de variáveis.

H1: o coeficiente de associação V de Cramer é diferente de zero, ou seja, existe relação entre o par de variáveis.

Portanto, utilizamos a seguinte regra, se Sig $>\alpha=0,05$ não rejeita $\mathrm{HO}$. Se Sig < $\alpha=0,05$ rejeitamos $\mathrm{HO}$ e aceitamos $\mathrm{H} 1$. Assim, pode-se verificar um aspecto interessante no caso brasileiro ao analisar a existência de associação entre as variáveis empreendedorismo e gênero. Utilizando a medida simétrica de aproximação de significância, verificamos que essa possui o valor de 0,001, ou seja, Sig< $\alpha$. Desta forma, rejeitamos $\mathrm{HO}$ e aceitamos $\mathrm{H} 1$ existindo associação entre as variáveis.

Com relação ao grau de força do indicador de associação das variáveis analisadas, identificou-se uma relação médiaiii ( $V$ de Cramer: 0.415) entre o gênero e o empreendedorismo (ver tabela 1).

Tabela 1 - Relação entre gênero e empreendedorismo no Brasil.

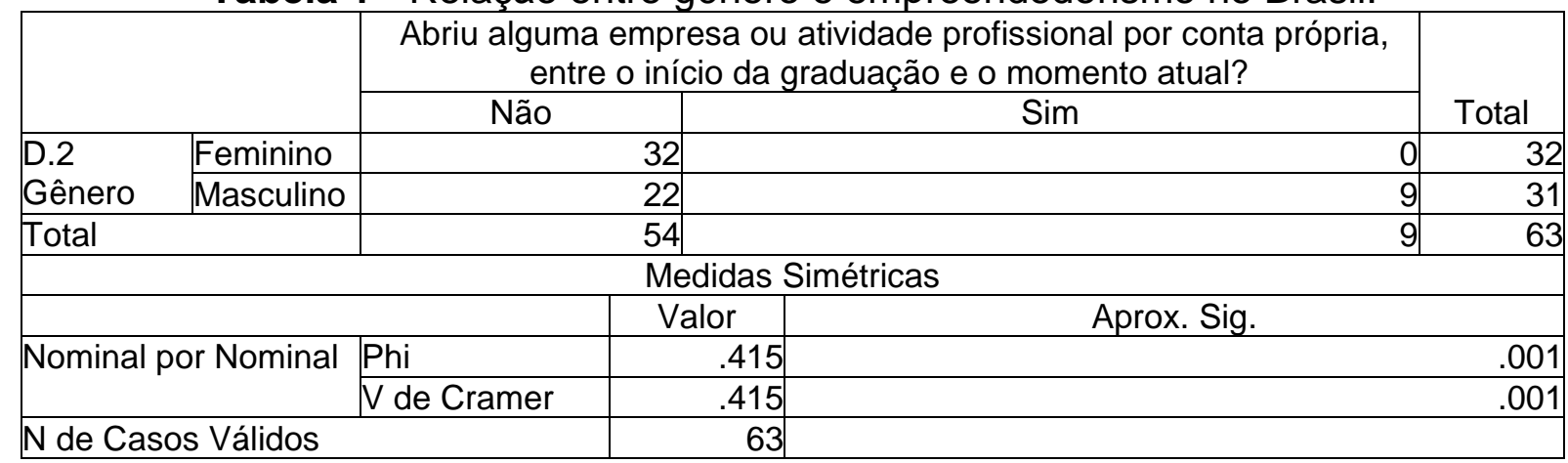

Fonte: Elaborado pelos autores. 
Desta relação, foi possível verificar que o sexo masculino possui uma maior relação com o empreendedorismo. Nesta pesquisa, entre os alunos que abriram alguma empresa ou iniciaram uma atividade profissional por conta própria, todos são do sexo masculino. Já em Portugal não foram encontradas relações entre as variáveis (ver tabela 2). Como a aproximação da significância $(0,622)$ é maior que alpha estipulado 0,05 , aceitamos $\mathrm{HO}$, ou seja, não há evidências estatísticas que comprovem a associação entre a variável sexo e empreendedorismo nos diplomados portugueses.

Tabela 2 - Relação entre gênero e empreendedorismo em Portugal.

\begin{tabular}{|c|c|c|c|c|c|}
\hline & \multicolumn{3}{|c|}{$\begin{array}{l}\text { Abriu alguma empresa ou atividade profissional por conta própria, } \\
\text { entre o início da licenciatura e o momento atual? }\end{array}$} & \multirow[b]{2}{*}{ Total } \\
\hline & & $\mathrm{N} / \mathrm{A}$ & Não & Sim & \\
\hline \multirow[t]{2}{*}{ D.2 Gênero: } & Feminino & 0 & 35 & 6 & 41 \\
\hline & Masculin & 1 & 37 & 6 & 44 \\
\hline Total & & 1 & 72 & 12 & 85 \\
\hline \multicolumn{6}{|c|}{ Medidas Simétricas } \\
\hline & & & Valor & Aprox. Sig. & \\
\hline \multirow{2}{*}{\multicolumn{2}{|c|}{ Nominal por Nominal }} & Phi & .106 & .622 & \\
\hline & & V de Cramer & .106 & 622 & \\
\hline
\end{tabular}

Fonte: Elaborado pelos autores.

Apesar do aumento da participação feminina no empreendedorismo brasileiro, alguns estudos observaram a maior propensão dos homens em empreender (CANEVER; KOHLS; LAGEMANN; RIGATTO, 2013; MATTHEWS; MOSER, 1996; PEÑALOZA; DIÓGENES; SOUSA, 2008; CRANT, 1996). Canever et al. (2013) acreditam que essa diferença entre gêneros pode estar associada ao papel social atribuído às mulheres. Shelton (2006) reconhece a existência de conflitos confrontados pelas mulheres que empreendem, especialmente a necessidade de conciliar trabalho e família.

Com relação ao fator, papel social atribuído as mulheres, para Perez-Quintana et al. (2017) a diferença da taxa de empreendedorismo feminino entre os países é causada por características andrógenas inerentes ao empreendedor. Para os autores, uma sociedade que consegue educar quanto capacidade de inovação e analítica, criatividade, e otimismo consegue, consequentemente, gerar uma taxa mais igualitária de empreendedorismo, pois tais fatores são mais determinantes para a intenção de empreender.

Assim, a percepção do papel do empreendedor também difere em cada cultura. Para Shneor, Camgöz e Karapinar (2013) em sociedade menos igualitárias entre os sexos (como no caso estudado a Turquia) há uma percepção que o empreendedor deve possui características semelhantes ao gênero masculino. De forma contrária, em sociedade mais igualitárias (como no caso a Noruega), existe uma percepção diferente das características inerentes ao empreendedorismo, sendo essa mais andrógena.

Portanto, a possível explicação da associação média entre o sexo masculino e o empreendedorismo no Brasil vem da desigualdade encontrada no país entre os sexos. O país encontra-se em $79^{\circ}$ lugar no ranking de 144 países, enquanto Portugal está em $31^{\circ}$ (WORLD ECONOMIC FORUM, 2016). Desta forma, há uma provável percepção andrógena no âmbito português sobre o empreendedorismo, que contribuem para o desenvolvimento de mulheres empreendedoras naquele país. 
Concluindo, ainda que as implicações familiares e sociais sejam um desafio para as mulheres empreendedoras, julga-se interessante para a UAB/Brasil realizar um estudo mais aprofundado, que vise compreender os motivos que levaram apenas os licenciados do sexo masculino a empreender, uma vez que, como já visto, o empreendedorismo pode contribuir significativamente para o desenvolvimento local sustentável.

\section{Considerações finais}

O empreendedorismo vem sendo reconhecido como um elemento fundamental para o desenvolvimento das nações e para a promoção dos sujeitos. Sendo uma temática de interesse das ciências da administração, cabe aos cursos desta área proporcionar condições favoráveis à educação empreendedora, por meio de ação de ensino, pesquisa e extensão (SILVA; GIL, 2015)

No caso dos cursos de administração/gestão a distância aqui pesquisados, averiguou-se que ambos possuem em sua grade curricular disciplinas específicas dedicadas à temática do empreendedorismo. Isto demonstra que, ao menos em nível formal, os cursos apresentam certa preocupação com o desenvolvimento da área e a consideram importante para a formação de seus alunos.

Verificou-se também que os índices de empreendedorismo entre os seus egressos rondam os $14 \%$ em ambos os países (gráficos 1 e 2). Ao comparar com à média nacional de cada país de empreendedores em estágio inicial $(9,5 \%$, em Portugal, 18,9\%, no Brasil) encontrou-se indícios de que em Portugal o impacto relativo do curso estudado foi maior. Entretanto, é importante resgatar que o aumento do empreendedorismo por necessidade elevou significativamente os indicadores brasileiros.

Os depoimentos dos entrevistados sugerem ainda que, dentre os egressos que empreenderam, os cursos influenciaram positivamente e contribuíram de maneira significativa para que a atividade empreendedora se efetivasse.

Portanto, ao considerar que esta pesquisa abrange estudantes de regiões periféricas, polos de ensino e centros locais de aprendizagem (CLAs) sediados em localidades pouco diversificadas economicamente, foram encontradas indicações sobre os contributos da educação a distância para o desenvolvimento de tais localidades, uma vez que o empreendedorismo pode dinamizar os arranjos sociais e econômicos locais.

Julga-se importante salientar que, embora tenha sido encontrado resultados positivos quanto empreendedorismo entre os alunos pesquisados, os índices de educação empreendedora não apresentam resultados robustos em ambos os países, sendo que os principais entraves para a atividade empreendedora são as políticas governamentais e as condições de educação e formação, como demonstram os já referenciados dados do mais recente Global Report (GEM, 2015/16). Para além disso, ressalta-se a forte predominância do sexo masculino nas atividades empreendedoras entre os diplomados do curso brasileiro.

Diante deste cenário, acredita-se que o alinhamento das Universidades no esforço para fomentar o empreendedorismo, não somente na sua vertente econômica, mas também social, assim como o empreendedorismo feminino, seria coerente e de 
grande valia, especialmente tratando-se de cursos de administração/gestão, campo em que o empreendedorismo está situado. Tal poderia contribuir significativamente para a melhoria dos índices de empreendedorismo e, desta forma, fomentar o desenvolvimento.

Vale destacar que, conforme argumentam Becker e Drew (2016), as Universidades, enquanto arranjos organizacionais inseridos amplamente na sociedade, possuem uma grande responsabilidade relativamente ao desenvolvimento social e econômico das comunidades, tendo em vista o seu potencial, como propulsora e fomentadora das capacidades empreendedoras e pesquisas voltadas a inovação.

Por fim, resgata-se o pensamento de Dolabela (1999, p. 14) ao ressaltar-se que "o empreendedorismo não deve ser encarado apenas como forma de enriquecimento pessoal. Ele deve ser direcionado para o desenvolvimento social, fazer com que as pessoas sejam incluídas e o país tenha mais condições de viver".

\section{Referências}

ABRANTES, P.; (Coord.); HENRIQUES, S.; JACQUINET, M.; NEVES, C. Ensino Virtual, Impactos Reais: Os percursos profissionais e de vida dos estudantes da Universidade Aberta (Projeto de Investigação). Universidade Aberta de Portugal, 2014.

ALBARELLO, L.; DIGNEFFE, F.; HIERNAUX, J. P.; MAROY, C.; RUQUOY, D.; SAINT-GEORGES, P. Práticas e métodos de investigação em ciências sociais. Lisboa: Gradiva, 1997.

ARETIO, L. G. La enseñanza abierta a distancia como respuesta eficaz para la formación laboral, $1997 . \quad$ Disponível em: http://espacio.uned.es/fez/eserv/bibliuned:20199/ensenanza_abierta.pdf. Acesso em: abril/2015.

BECKER, R. G.; DREWS, G. A. Práticas de docência orientadas para a inovação e empreendedorismo: análise sob as práticas e perspectivas dos docentes de Administração da UNIJUÍ. Salão do Conhecimento, v. 2, n. 2, 2016.

BOSMA, N. et al. GEM Global Report 2019/2020. GEM Global Report, [S. I.], p. 232, 2019.

BUNN, D. A.; SILVA, E. A. S. Guia do estudante. Florianópolis: Departamento de Ciências da Administração/UFSC, 2014.

CANEVER, M. D.; KOHLS, V. K.; LAGEMANN, M.; RIGATTO, P. Empreendedorismo: por que alguns estudantes e não outros escolhem ser empreendedores? Estudos e Pesquisas em Psicologia, v.13, n.1, p. 101-124, 2013.

CASADO, F. L.; SILUK, J. C. M.; ZAMPIERI, N. L. V. Universidade empreendedora e desenvolvimento regional sustentável: proposta de um modelo. Rev. Adm. UFSM, Santa Maria, v. 5, Edição Especial, p. 633-650, Dez. 2012. 
CAVALCANTI, M.; GOMES, E. Inteligência Empresarial: Um Novo Modelo de Gestão para a Nova Economia. Produção, v.10, n.2, p.53-64, maio 2001.

CHAN, K.-Y. et al. Who Wants to Be an Intrapreneur? Relations between Employees' Entrepreneurial, Professional, and Leadership Career Motivations and Intrapreneurial Motivation in Organizations. Frontiers in Psychology, [S. I.], v. 8, p. 2041, 2017. Disponível em: https://doi.org/10.3389/fpsyg.2017.02041

COSTA, D. M.; BARBOSA, F. V.; SILVA, C. H. P. Empreendedorismo e inovação: o papel da educação superior nas economias mundiais. Anais do XI Colóquio Internacional sobre Gestão Universitária na América do Sul. Anais... In: XI COLÓQUIO INTERNACIONAL SOBRE GESTÃO UNIVERSITÁRIA NA AMÉRICA DO SUL. Florianópolis: IGLU, 2011

CRANT, J. M. The proactive personality scale as a predictor of entrepreneurial intentions. Journal of small business management, v.34, n.3, p. 42-49, 1996.

CRISSIEN, J. O. Estrategias pedagógicas para despertar el espíritu emprendedor. Rev. esc.adm.neg., [S. I.], n. 71, p. 100-125, 2013.

DALFOVO, M. S.; LANA, R. A.; SILVEIRA, A. Métodos quantitativos e qualitativos: um resgate teórico. Revista Interdisciplinar Científica Aplicada, v.2, n.4, p. 01-13, 2008.

DCSG: Departamento de Ciências Sociais e Gestão. Licenciatura em Gestão (1 Ciclo). Guia de Curso. (2015/2016). Disponível em: https://www2.uab.pt/guiainformativo/guias curso/lg guia de curso 2015.pdf Acesso em: maio/2015.

DOLABELA, F. Oficina do empreendedor: metodologia de ensino que ajuda a transformar conhecimento em riqueza. 6 ed. São Paulo: Editora de Cultura, 1999.

DWIVEDI, A. K. Distance and Online Entrepreneurship Education in India. SSRN Electronic Journal, [S. I.], 2017. Disponível em: https://doi.org/10.2139/ssrn.2992018. Acesso em: 8 maio. 2020.

EBAPE. Equivalência ECTS - Disciplinas EBAPE. Disponível em: https://ebape.fgv.br/sites/ebape.fgv.br/files//equivalencia-ects.pdf Acesso em: junho/2017.

ETZKOWITZ, H. The Triple Helix of University-Industry-Government Implications for Policy and Evaluation. Science Police Institute, 2002.

ETZKOWITZ, H.; MELLO, J. M. C.; ALMEIDA, M. C. Towards meta innovation in Brazil: The evolution of the incubator and the emergence of a triple helix. Research Policy, Amsterdan, v.34, n.4, p. 411-424, 2005.

FERREIRA, Carlos Eduardo Moreira. A importância do acesso à tecnologia. Interação, Boletim Informativo do IEL. Ano 9, no 105, dez. 2000. 
FORMIGA, M. M. M. A terminologia da EAD. In: Litto Michael Fredric; Formiga, Manuel Marcos Maciel (orgs.). Educação a distância: o estado da arte. São Paulo: Pearson Education do Brasil, 2009.

GEM. Global Entrepreneurship Monitor: Global Report. (2015/16). Disponível em: http://www.gemconsortium.org/report/49480 Acesso em: julho/2016.

GEM-BRASIL. Global Entrepreneurship Monitor: empreendedorismo no Brasil 2015 (Relatório executivo). (2015). Disponível em: http://www.bibliotecas.sebrae.com.br/chronus/ARQUIVOS CHRONUS/bds/bds.nsf/c 6de907fe0574c8ccb36328e24b2412e/\$File/5904.pdf Acesso em: julho/2016.

GEM-PORTUGAL. GEM Portugal 2013|2004-2013: uma década de empreendedorismo em Portugal. (2013). Disponível em: https://repositorio.iscteiul.pt/handle/10071/8058 Acesso em: julho/2016.

GURI-ROSENBLIT, S. Distance Education and E-Learning: not the Same thing. Higher Education: The International Journal of Higher Education and Educational Planning, v. 49, n.4, p. 467-493, 2005.

HENRIQUE, D. C.; CUNHA, S. K. Metodologias, Recursos e Práticas DidáticoPedagógicas no Ensino de Empreendedorismo em Cursos de Graduação e PósGraduação Nacionais e Internacionais. Anais do $30^{\circ}$ Enanpad. Anais... In: $30^{\circ}$ ENCONTRO DA ASSOCIAÇÃO NACIONAL DE PESQUISA E PÓS-GRADUAÇÃO EM ADMINISTRAÇÃO. Salvador: 2006

HERMIDA, J. F., BONFIM, C. R. D. S. A educação à distância: história, concepções e perspectivas. Revista HISTEDBR On-line, Campinas, n. especial, 166-181, 2006.

HUOT, R. Métodos quantitativos para as ciências humanas. Lisboa: Instituto Piaget, 2002.

LAPA, A. B. A ação dialógica na Educação a Distância. Revista Tecnologia e Sociedade, 4(4), p. 113-134, 2007.

LAUREANO, R, M. S. Teste de hipóteses com o SPSS - O meu manual de consulta rápida. Lisboa: Edições Sílabo, 2013.

LÜCK, E. H. Educação a distância: contrapondo críticas, tecendo argumentos. Revista Educação, (31) 3, 258-267, 2008.

MARKOVIĆ, M. M. R. et al. E-Learning as a Tool for Empowering Entrepreneurship. Journal of Women's Entrepreneurship and Education, [S. I.], n. 3, p. 65-72, 2017.

MATTHEWS, C. H.; MOSER, S. B. A longitudinal investigation of the impact of family background and gender on interest in small firm ownership. Journal of small business management, v. 34, n.2, p.29-43, 1996.

MAURO, R. A. et al. Educação a distância: contribuições da modalidade para uma qualificação empreendedora. Revista de Gestão e Projetos - GeP, [S. I.], v. 8, n. 3, p. 118-128, 2017. 
MOORE, M. G; KEARSLEY, G. Distance education: a systems view of online learning. USA: Cengage Learning, 2012.

MOROSINI, M. A Universidade no Brasil: concepções e modelos. 2. ed. INEP: Brasília, 2011. Disponível em: < http://www.publicacoes.inep.gov.br/portal/download/443>. Acesso em: 30 mai. 2017.

NUNES, I. B. A história da EaD no mundo. In: Litto, F. M; Formiga, M. M. M. (orgs). Educação a distância: o estado da arte. São Paulo: Pearson Education do Brasil, 2009.

OLIVEIRA, A, M. G.; MELO, M. C. O. L.; MUYLDER, C. F. Educação empreendedora: O desenvolvimento do empreendedorismo e inovação social em Instituições de Ensino Superior. Revista Administração em Diálogo - RAD, v.18, n.1, 2016.

PEÑALOZA, V., DIÓGENES, C.; SOUSA, S. Escolha profissional no curso de administração: tendências empreendedoras e gênero. RAM. Revista de Administração Mackenzie, v.9, n.8, p.151-167, 2008.

PENEDO, A. S. T.; PEREIRA, V. S. Distance education: advantages and disadvantages of the point of view of education and society. Dialogia, [S. I.], n. 29, p. 139-152, 2018.

PEREZ-QUINTANA, A. et al. The influence of sex and gender-role orientation in the decision to become an entrepreneur. International Journal of Gender and Entrepreneurship, v. 9, n. 1, p. 8-30, 2017.

QUIVY, R.; CAMPENHOUD T, L. V. Manual de investigação em ciências sociais. Lisboa:

REIS, E. Estatística descritiva. Lisboa: Sílabo, 1996.

RIBEIRO, R. L.; OLIVEIRA, E. A. A. Q.; ARAUJO, E. A. S. A contribuição das instituições de ensino superior para a educação empreendedora. Revista Brasileira de Gestão e Desenvolvimento Regional, v.10, n.3, 2014.

SARKAR, S. O empreendedor inovador: faça diferente e conquiste seu espaço no mercado. Rio de Janeiro: Elsevier, 2008.

SCHUMPETER, Joseph A. The Theory of Economic Development: an inquiry into profits, capital, credit, interest, and the business cycle (1911). Transaction Publishers: Nova lorque, v.1, p. 244, 1982.

SCHUMPETER, Joseph Alois. Business cycles: a theoretical, historical, and statistical analysis of the capitalist process. McGraw-Hill, 1939.

SHELTON, L. M. Female Entrepreneurs, Work-Family Conflict, and Venture Performance: New Insights into the Work-Family Interface. Journal of small business management, v. 44 n.2, p.285-297, 2006. 
SHNEOR, R.; CAMGÖZ, S. M.; KARAPINAR, P. B. The interaction between culture and sex in the formation of entrepreneurial intentions. Entrepreneurship \& Regional Development, v. 25, n. 9-10, p. 781-803, dez. 2013.

SILVA, A. L. As concepções de formação para autonomia na educação a distância: olhares a partir da teoria crítica da sociedade. Dissertação de mestrado em educação. Universidade Federal de Lavras, Lavras, 2014.

SILVA, E. L.; MENEZES, M. E. Metodologia da pesquisa e elaboração de dissertação. 3. ed. Florianópolis: Laboratório de ensino a distância da Universidade Federal de Santa Catarina, 2001.

SILVA, S. P. M.; GIL, A. C. O Método Fenomenológico na Pesquisa sobre Empreendedorismo no Brasil. Revista de Ciências da Administração, v. 1, n. 1, p. 99, 2015.

SILVEIRA, Rafael Alcadipani da. Academia e a fábrica de sardinha em lata. Organização \& Sociedade, Salvador, UFBA, v.18, n.54, p.345- 348, abr./jul 2011.

SIMONSON, M. Teoría, investigación y educación a distancia. In: Barberà, E. Educación abierta y a distancia. Barcelona: UOC, 2006.

SOLÓRZANO-GARCÍA, M.; NAVÍO-MARCO, J. Developing social entrepreneurs through distance education: the value of commitment and interactivity with the learning community. Int. J. Mobile Learning and Organisation, [S. I.], v. 13, n. 1, p. 21, 2019.

SOUZA, A. C.; FIALHO, F. A. P.; OTANI, N. TCC: métodos e técnicas. Florianópolis: Visual Books, 2007.

SOUZA, E. C. L. et al. Métodos, técnicas e recursos didáticos de ensino do empreendedorismo em IES brasileiras. In: SOUZA, E. C. L.; GUIMARÃES, T. A. (Eds.) Empreendedorismo além do plano de negócio. São Paulo: Atlas, 2006.

TEZZA, G. O. A.; SILVEIRA, A.; HOELTGEBAUM, M. A educação empreendedora nos cursos de graduação em administração de Santa Catarina e do Paraná, Brasil. In: SILVEIRA, A.; DOMINGUES, M. J. C. de S. (Eds.). Ensino na área de administração e avaliação de instituições de ensino superior. Blumenau: Edifurb, 2006.

WORLD ECONOMIC FORUM. The Global Gender Gap Report. World Economic Forum, 2016.2 Disponível em: <http://www3.weforum.org/docs/GGGR16/WEF_Global_Gender_Gap_Report_2016. pdf $>$. Acesso em: 20 jan. 2017.

i A EBAPE (2014) convenciona a equivalência de 7,5 ECTS para uma disciplina de 60 horas. Desta forma, uma disciplina com 6 ECTS seria equivalente a 48 horas

ii A atividade empreendedora early-stage é composta por empreendedores nascentes, ou seja, que estão envolvidos na constituição de um negócio ou são proprietários de um novo negócio com até 3,5 anos (GEM, 2015/16).

iii Utilizamos os seguintes parâmetros para verificar o grau de associação entre as variáveis: Inexistência de relação (Aprox. Sig =0); Insignificante (]$|0-0,2|[)$; Fraca $([|0,2-0,4|[)$; Média $([\mid 0,4-$ $0,7 \mid[)$; Forte [|0,7 - 1|[); relação determinística (|1|) (LAUREANO, 2013). 